\title{
HEDGING RISK IN AGRICULTURAL FUTURES MARKETS
}

\author{
Joost M.E. Pennings ${ }^{1}$ and \\ Matthew T.G. Meulenberg ${ }^{1}$
}

\section{Introduction}

Futures contracts are potential price-risk management instruments for farmers. While much research has been done on the valuation of these instruments, little is known about the risks of using futures contracts. When hedging, farmers must be aware of these risks associated with hedging which we analyze in this article. By analyzing the capacity of futures contracts for reducing risk, we provide both the management of the futures exchange and the hedger a better understanding of the pro and cons of futures contracts as instruments for price-risk reduction.

There are two general sources of risk to farmers ${ }^{2}$, quantity risk and price risk. Quantity risk is a farm-specific phenomenon caused by a myriad of random factors such as, disease and weather conditions. Price risk is a market phenomenon caused by random changes in the aggregate quantity of a good demanded or supplied (Dwight, 1985). This article focuses on price risk. This type of risk has become more relevant to farmers in both the United States (U.S.) and the European Union (E.U.) because of the free-trade policy of GATT and reforms in the common agricultural policy of the E.U.

Because of increased fluctuations in agricultural prices, some exchanges are creating new futures contracts. Recently, the Marche a Terme International de France in Paris and the Amsterdam Agricultural Futures Exchange have introduced rapeseed futures contracts and wheat futures contracts, respectively. On the one hand, price risk in the cash market can be decreased using futures, while on the other hand, futures generate additional risks. Understanding the capacity of futures to reduce overall risk is important. (Jolly, 1983; Bosch and Johnson, 1992). Actually, the lack of understanding by farmers and firms, in general, about how to use futures has caused many failures in price-risk management (Figlewski, Landskroner and Silber, 1991; Edwards and Canter, 1995).

The contribution of this article on price-risk management by farmers is two-fold. 
First, in contrast to other studies, this article takes into account that futures not only reduce cash price risk but also introduce hedging risk ${ }^{3}$. This element of hedging efficiency has a great influence on the capacity of the futures contract to eliminate overall risk. Second, hedging risk is analyzed in all of its components. Furthermore, the influence of the interaction between those components on the hedging risk is examined.

The paper is organized as follows. First, a general framework of hedging efficiency is proposed. Second, the risks introduced by futures are analyzed. In order to illustrate how large the hedging risk can be for farmers using futures, the hedging risk for the potato futures contract traded on the Amsterdam Agricultural Futures Exchange is measured.

\section{Hedging Efficiency}

Three hedging theories can be distinguished. First, traditional hedging theory emphasizes the potential of futures markets to avoid risk: cash positions are hedged by taking an equal but opposite position in the futures market. A second theory (Working, 1962) suggests that hedgers operate like speculators, being primarily interested in relative prices rather than absolute ones. According to Working, holders of a long position in the cash market hedge if they expect the basis to fall, but not when a rise is expected. The latest and the most common theory nowadays is the portfolio approach. In this approach the risk of price changes is introduced into the hedging model by a variance function. Moreover, a frontier is traced, showing a relationship between variance and expected returns.

The recently proposed measures of hedging effectiveness are based on the third hedging approach mentioned above. Several studies (e.g., Ederington, 1979; Franckle, 1980; Hill and Schneeweis, 1982; Wilson, 1984; Howard and D'Antonio, 1984; Chang and Shanker, 1986; Overdahl and Starleaf, 1986; Lindahl, 1989; Chang and Fang, 1990; Gjerde, 1987; Pirrong, Kormendi and Meguire, 1994; Hsin, Kuo and Lee, 1994) describe the usefulness of trading a futures contract by comparing the results of a combined cash-futures portfolio and the cash position only.

Ederington (1979) defines hedging effectiveness as the reduction in the variance of returns. The objective of a hedge is to minimize the risk of a given position. This risk is represented by the variance of returns. Howard and D'Antonio (1984) derive a measure of hedging effectiveness that incorporates both the minimization of risk and maximization of the excess return (e.g., Chang and Shanker, 1986; Lien, 1993). Hsin, Kuo and Lee (1994) measure hedging effectiveness as the difference in the certainty equivalent returns between the hedged position and spot position. This approach considers both risk and returns in hedging. They argue that the advantages of their measure are that it considers both risk and expected returns and that it is consistent regardless of the empirical expected changes in spot prices. 
These measures are concemed with the minimizing the risk of the portfolio of the spot commodity and the futures contract or finding an optimal balance between risk and return. All these measures implicitly assume that the futures contract is perfect, i.e., introduces no risks. However, futures contracts do introduce risks which have an impact on the variance of the hedger's returns. Furthermore, these risks affect the success of a futures contract and are, therefore, of great interest both to the management of the futures exchange and the hedger (Black, 1986).

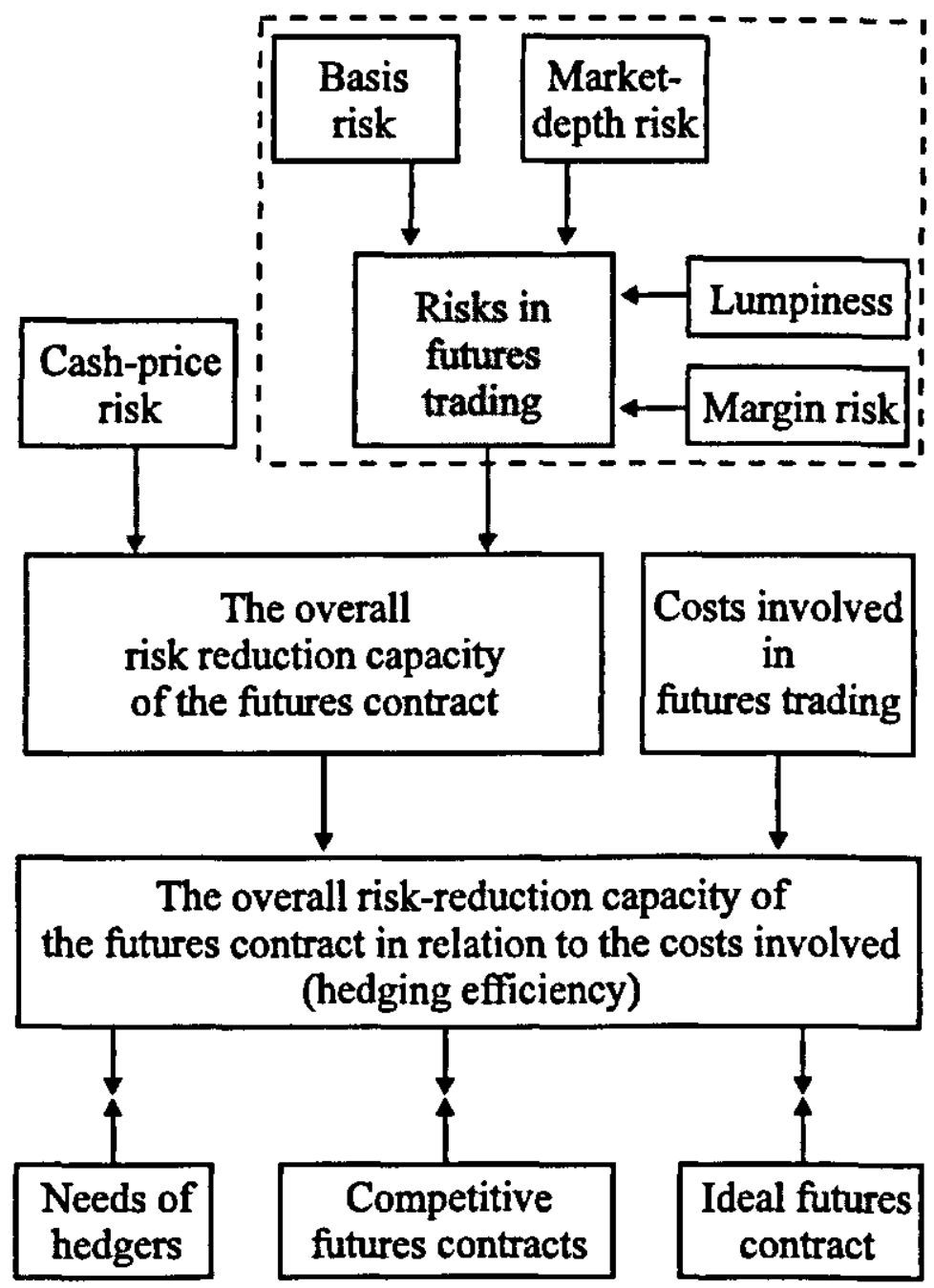

Figure 1: $\quad$ Proposed concept of Hedging Efficiency

A futures contract which establishes a certain price without introducing other risks best fulfills the hedger's need for hedging. However, the hedger will not always use 
this particular futures contract, since the decision is also influenced by the cost involved in futures trading, i.e., commission costs and margin requirements.

The hedger will weigh the costs involved in futures trading against the satisfaction he derives from the futures contract. Therefore, we propose to define hedging efficiency as the capacity of the futures contract to reduce the overall risk in relation to the cost involved in futures trading. It is important for both the futures exchange and the hedger to know how well the services provided by the futures contract meet the needs of the hedger. The proposed concept of hedging efficiency assesses how well the futures exchange is able to achieve this goal. Figure 1 illustrates our concept of hedging efficiency.

The capacity of the futures contract to reduce total risk in relation to the trading costs involved is the hedging service which the futures exchange provides. Two factors are important for the futures exchange: whether it meets the need of the hedgers with respect to overall risk reduction, and whether it can compete on that point with competitive futures exchanges. In this article, we elaborate on the futures trading risk, i.e., the upper-left part of Figure 1 denoted by the dotted line.

\section{Risks in Futures Trading}

Because the futures market offers a price-risk-management service, this service preferably should not generate additional risk. When the futures market introduces no hedging risk we refer to the futures contract as a perfect futures contract which generates a price for the short hedger in period $t+l$ of:

[1] $A R P_{t+1}=C P_{t+1}+\left(P F_{t}-P F_{t+1}-T C\right)=P F_{t}-T C$

where $A R P$ is the actual realised price, $C P$ the local cash price, $P F$ the futures price, $P F_{t}-P F_{t+1}$, the liftings value and $T C$ the roundturn brokerage costs

However, in practice we observe that the actual price realised $A R P_{t+}$, is often not equal to the net futures price $P F_{t}-T C$ for which the hedger enters the futures market. Hence, the hedger is exposed to hedging risk, where hedging risk is defined as the distance between the price for which the hedger enters the futures market corrected for transaction costs, $P F_{t}-T C$, and the actual price after the hedger has liquidated the futures position, $A R P_{t+1}$, regardless of whether this distance is positive or negative (Camerer and Kunreuther, 1989).

Hedging risk can be broken down into the following elements: basis risk, lumpiness, market-depth risk and margin risk. These elements are analyzed for hedging price risk for farmers. 


\subsection{Basis Risk}

It is generally recognized that futures markets can be used by farmers to hedge the risks associated with price fluctuations in the underlying spot market (Grossman, 1986). Any deviation in the cash-futures-price relationship at the settlement date will be eliminated. However, if the arbitrage transaction costs are high, the necessary convergence of the cash and futures prices will be countered, thereby introducing a risk to the hedger and negatively affecting participation in futures markets. The basis between a futures contract and its underlying commodity is an important measure of the cost of using the futures contract to hedge. In a crosshedge, the relative size of the basis of alternative hedging vehicles often plays a decisive role in the selection of the optimal hedging vehicle (Castelino et al., 1991). Basis risk is attributed to location, quality and timing discrepancies between commodities traded in the cash market and those deliverable on futures (Paroush and Wolf, 1989). In the case of futures indexes, unanticipated variation in dividends may involve basis risk (Figlewski, 1984; Brennan and Schwartz, 1990). The unpredictability of the basis presents hedgers with a risk that is unhedgable, as is outlined by Figlewski (1984) and Brennan and Schwartz (1990). Explanations for the variability in the basis include the marking-to-market requirement for futures contracts, the differential tax treatment of spot and futures, as well as the difficulties in arbitrating between large cash positions and futures. Kumar and Seppi (1994) find that arbitrage reduces basis volatility.

The existence of basis risk, which is specific to futures markets and does not exist in cash forward markets, introduces an element of speculation in the sense that hedgers are still exposed to this risk while hedging their physical commodity. In a recent article, Netz (1996) shows that basis risk not only affects the futures position but also the cash-market position for all hedging by risk-averse agents. Numerous articles provide statistical models for predicting the basis (Naik and Leuthold, 1988; Trapp and Eilrich, 1991; Liu et al., 1994), although researchers find it difficult to forecast.

\subsection{Lumpiness}

Farmers can specify forward contracts which correspond with the quantity they have available for sale, in contrast to futures contracts which are traded in standard quantities. Therefore, a futures hedge may not exactly match the amount of the desired sale or purchase, and lumpiness causes a proportion of the cash position to remain exposed to uncertain changes in price. As the quantity to be hedged increases, the relative importance of lumpiness declines and ultimately approaches zero.

\subsection{Market-depth Risk}

Market-depth risk is the risk the hedger faces from a sudden price decrease or increase due to order imbalances; this risk seems important to systematic hedgers, particularly in thin markets. Kyle (1985) defines market depth as the volume of 
unanticipated order flows which move prices by one unit. Sudden price changes may occur in cases of both long and short hedges. If a relatively small market sell (buy) order arrives, the transaction price is the bid (ask) price. For a relatively large market sell (buy) order, several transaction prices are possible, at lower and lower (higher and higher) prices, depending on the size of the order and the number of traders available. If the sell order is large, the price should continue falling to attract additional traders to take the other side of the order. Given a constant equilibrium price in a deep market, relatively large market orders result in a smaller divergence in transaction prices from the underlying equilibrium price than in a thin market. The generally known factors which determine market depth, and in general liquidity, include: the amount of trading activity ${ }^{3}$ or the time rate of transactions during the trading period; the ratio of trading activity by speculators and scalpers to overall trading activity; equilibrium price variability; the size of a market order (transaction); expiration-month effect; and market structure ${ }^{6}$ (Black, 1986; Thompson and Waller, 1987; Christie and Schultz, 1994; Chan and Lakonishok, 1995; Christie and Schultz, 1995). According to Lippman and McCall (1986) the deepness of the market for a commodity increases with the frequency of offers. Hasbrouck and Schwartz (1988) report a relation between market depth and trading strategies of market participants. Passive participants wait for the opposite side of their trade to arrive, but the active ones seek immediate transaction. Passive participants may avoid depth costs, whereas active ones generally incur depth costs. Some exchanges monitor temporary order imbalances, i.e., market-depth risk, and slow down the trade process if these are present (Affleck-Graves, Hegde and Miller, 1994). For example, an order-book official issues warning quotas when trading results in price changes that are larger than minimums allowed by the exchange and halts trading when order execution results in price changes that exceed exchangemandated maximums (Lehmann and Modest, 1994). Market-depth measures are rather scarce. Brorsen (1989) uses the standard deviation of the log price changes as a proxy for market depth. Lehmann and Modest (1994) study market depth by examining the adjustment of quotas to trades and the utilization of the chui kehai trading mechanism on the Tokyo Stock Exchange, where the chui kehai are warning quotas when a portion of the trade is executed at different prices. Utilizing the chui kehai trading mechanism can give an indication of market depth, but cannot be used to measure it. Other researchers, such as, Bessembinder and Seguin (1993), use both price volatility and open interest as a proxy for market depth. In general, an individual farmer who manages a family farm needs only a few futures contracts to hedge his underlying cash position because of the large size of the futures contract relative to the cash position. For that reason, the market depth costs are probably relatively small. However, for traders or cooperatives that wish to hedge price risks on behalf of a group of farmers, market depth costs may be large. Farmers can eliminate market depth costs if they give orders with limit prices to a broker. However, if they use limit prices, farmers may run the risk that their trade cannot be executed. 


\subsection{Margin Risk}

The net cost arising from futures margin requirements consists of the opportunity costs of the initial margin requirement and the opportunity cost of marking to market (i.e., marking to market means that if futures prices fluctuate, those who hold losing positions must add to their margin accounts, while winners may withdraw their surpluses). Farmers holding losing positions incur actual and opportunity interest costs. These income and cost flows compound over the span of the futures hedge. The margin cost is more significant if the time horizon of the hedge increases. Thus, futures in agricultural commodities with relatively long growth and storage periods, such as, potatoes (with a time horizon of about one year), incur more margin costs than hogs, where there is no storage period and the growth period is short (with a time horizon of about three months).

\subsection{Model}

In order to gain insight into the consequences of hedging risk for the farmer, a microeconomic approach is adapted to hedging. In this article, risk is measured by the variance which is a measure of how much the outcomes vary or differ from one another. Hence, the variance corresponds exactly with (hedging) risk as defined at the beginning of this section.

Consider a farmer who systematically hedges his output and intends to sell the output in period $T$ on the cash market. The farmer can now use futures based on different strategies to manage price risk. The strategy of a farmer depends on whether the desired time period $T$ equals the maturity of the futures $M$. If $T=M$, the farmer offsets his position and sells the commodity in the cash market or he holds the position and makes delivery ${ }^{7}$. Whether the farmer offsets his position or makes delivery depends on the standardization requirements, the search cost in the cash market, and the market-depth cost in the futures markets. If $T \neq M$, the farmer can only liquidate his position by offsetting the original futures contract. Figure 2 depicts the decision tree of the farmer for hedging output with futures.

Temporal situation
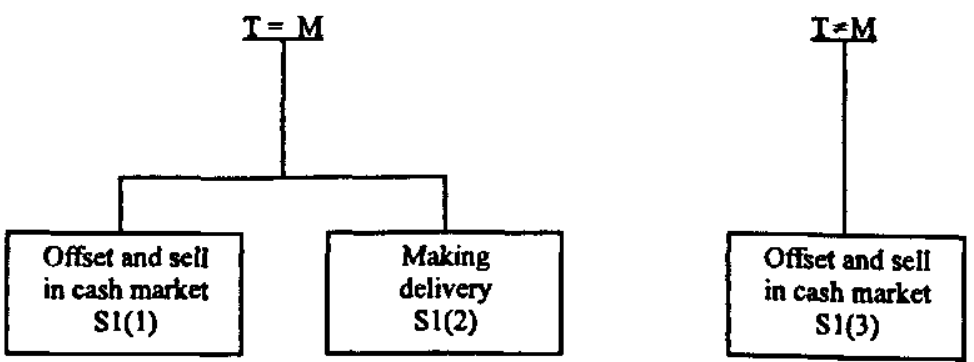

Figure 2: Hedging strategies in the case of futures. 
The revenue of a farmer who hedges his output when the delivery date for the commodity equals the maturity date of the futures can be expressed as:

[2] $\tilde{\Pi}_{l}=n\left(P F_{l}-\tilde{C} P_{T}\right)+(q-n) \tilde{C} P_{T}+n \tilde{C} P_{T}+n \tilde{B}_{T}^{s q}-n \tilde{M} D C-n T C-I^{\epsilon}-n \tilde{I}^{m m}$

where $\Pi_{I}$ is the revenue at the end of the period when the delivery date for the commodity equals the maturity of the futures, $n$ is the futures quantity sold, $q$ is the output produced, $B_{7}^{\varphi q}$ is the spatial and quality dimensions of the basis at the end of the period, $M D C$ the market-depth costs, $I^{\epsilon}$ is the initial margin costs and $I^{m m}$ is the marking-to-market costs. A tilde $(\sim)$ denotes a random variable. Lumpiness is expressed as $q-n$, i.e., the quantity which cannot be hedged because of the standardized units of the futures contract.

We assume that the farmer wishes to hedge his underlying cash position completely. It can be shown that a full hedge is not always optimal for the hedger. However, for simplication, we assume a full hedge, which does not affect our conclusions.

The revenue of a farmer who hedges his output when the delivery date of the commodity is unequal to the maturity date of the futures can be expressed as:

[3] $\tilde{\Pi}_{2}=\tilde{\Pi}_{l}+\tilde{n} B_{T}^{t e m}$

where $\Pi_{2}$ is the revenue at the end of the period when the delivery date for the commodity is unequal to the maturity date of the futures contract, and $B_{T}^{\text {tem }}$ is the temporal dimension of the basis.

To determine the hedging risk, it is necessary to determine the covariance matrix of the stochastic variables contributing to the hedging risk. The covariance matrix can be represented by:

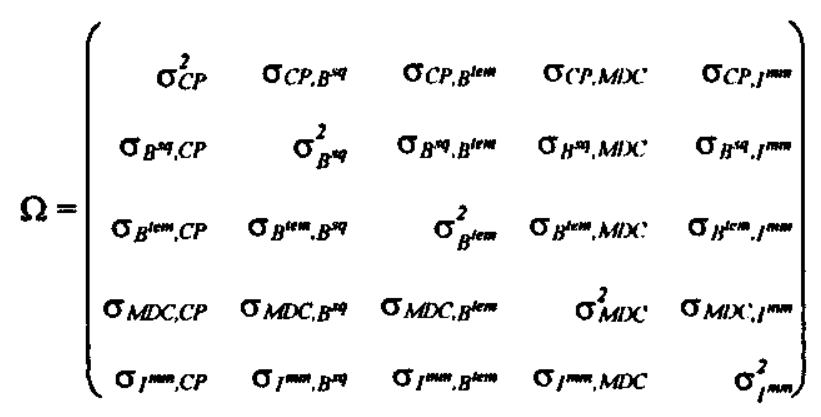

where $\sigma_{x}^{2}$ represents the variance of the random variable $x$, and $\sigma_{x y}$ represents the covariance between the random variables $x$ and $y$. 
By letting $b^{\prime}=(q-n, n,-n,-n)$, the variance of the revenue can be expressed as:

$$
\sigma_{\Pi_{2}}^{2}=b^{\prime} \Omega b \text {. }
$$

The covariance matrix provides insight into the underlying structure of hedging risk. If there is no lumpiness, i.e., $n$ equals $q$, the influence of cash-price uncertainty can be entirely eliminated. Thus, for large farmers and cooperatives which represent a group of farmers, the lumpiness will not be large. However, if a large farmer or cooperative enters the market with many contracts, in contrast to a small farmer who enters the futures market with only a few futures contracts, they may face marketdepth-cost risk. With a large cash-market position and, hence, many futures, the cash-price risk caused by the lumpiness is relatively low, but the market-depth-cost risk may be relatively high. Knowing the characteristics of the underlying structure of market-depth cost is helpful in order to reduce this risk (Pennings et al., 1996).

The interaction between the components of the hedging risk are represented by the covariances. For the hedger it is important to understand the interactions between the hedging risk components. For example, from a theoretical point of view, it is expected that the covariance between the basis (both the temporal dimension and spatial and quality dimension) and the market-depth costs influence the variance of the revenue when the futures market is relatively thin and the underlying commodity of the futures contract is not exactly equal to the cash position of the hedger. An example makes this clear. Suppose a potato producer goes short the April 1996 contract traded on the Amsterdam Agricultural Futures Exchange at 30 Dutch Guilders. Now, suppose that in April 1996 when he enters the market to lift his hedge, the current basis is 0.5 Dutch Guilders. He buys to cover his short position, and because of a lack of market depth, the transaction pushes the price upward, so that the actual basis is 0.1 Dutch Guilders. Thus, the market-depth-cost risk has actually decreased the hedging risk and, hence, improved the hedging effectiveness (Pennings and Meulenberg, 1997).

The covariance matrix not only provides information for hedgers but also for the management of the futures exchange. The futures exchange has tools, such as the futures contract specification and the trading system, which may affect the elements of the covariance matrix thereby affecting the hedging efficiency (Pennings and Meulenberg, 1997). For example, the basis may, to some extent, be managed by the futures exchange. A futures contract specification which resembles the cash position reduces basis risk. The futures exchange can also reduce market-depth risk by using a mechanism to slow down the trading process if order imbalances occur and to attract market depth by reporting these. Also, order book information may be improved; one mechanism that allows potential participants to view real-time limit orders, by displaying the desired prices and quantities at which participants would like to trade, affects market depth because participants can now observe how many contracts can be traded at the quoted price. We conclude that insight into the covariance matrix provides the hedger information about the risk he is facing when 
using futures and provides the management of the futures exchange with insight into their hedging services. To determine the hedging risk for potato growers, we conducted a simulation by applying our model to data from the Amsterdam Agricultural Futures Exchange.

\section{Empirical lllustration}

The hedging risk is measured using data on the potato futures contract traded at the Amsterdam Agricultural Futures Exchange (ATA). The potato futures contract is a relatively successful. In fact, the volume generated is large relative to competitive potato futures contracts in Europe. With the aid of transaction-specific data, it was possible to measure the hedging risk run by trading potato futures contract for delivery April 1996. Because only transaction-specific data for period February 1995 to June 1995 were available, the time horizon of the simulation was limited. Thus, no distinction could be made between the temporal basis and the spatial and quality basis. The period captured the preharvest period for potato growth and the marketing cycle. This implied that the basis between the cash prices for February to June 1995 and the price of futures for April 1996 included the full storage costs for the harvest period of September 1995 to April 1996. Therefore, changes in the basis in the sample period are not due to changes in storage costs. It is assumed that the estimated variance between the cash price and of the basis in the sample were constant over time because these are characteristics of the market.

The covariance matrix $\Omega$ was calculated using the Rotterdam potato cash prices, the closing prices for potato futures and on the basis of transaction-specific data collected by the clearing corporation. The market-depth costs for an order selling imbalance were calculated as the area between the downward-sloping price path and the price for which the hedger enters the futures market,

[4] $M D C=P F^{\prime *} N-\sum_{i=1}^{N}\left(P F^{i}\right)$

where $P F^{\prime}$ is the futures price for which the hedger enters the market and $N$ the total order flow.

The market-depth costs for an order buying imbalance were calculated as the area between the upward-sloping price path and the price for which the hedger enters the futures market,

$$
M D C=\sum_{i=1}^{N}\left(P F^{i}\right)-P F^{\prime *} N
$$

From the data, it was impossible to infer the exact split between an increasing and decreasing price path, since prices were constant for several contracts in the local minimum or maximum. Therefore, we followed the following procedure: for an odd number of intersecting contracts we used the middle contract, whereas for an even number of constant contracts a random assignment with equal probabilities was used 
to determine the split. Subsequently, all order-specific market-depth costs were converted into daily market-depth costs per futures contract. The margin costs depend on the price of the futures contracts sold. The margin costs were calculated for several prices on the basis of an interest rate of $5 \%$ for borrowing and an interest rate of $4 \%$ for investing.

The amount of output which the farmer wishes to hedge $q$, the output produced $n$ and the price which the farmer has locked in the futures market $P F$ were specified ex ante (see Table 1).

Table 1: Research design for calculating the variance of returns in case of price risk management by futures for different values of the futures position $n$, cash position $q$ and futures price $P F$.

\begin{tabular}{lll}
\hline$n$ & $q$ & $P F$ \\
\hline$n_{1}=1$ & $q_{1}=1$ & $P F_{i}=23,24,25,26,27$, \\
& & $29,31,33,35,40,45,50$, \\
$n_{2}=1$ & $q_{2}=1.5$ & $55,60,65,70,75$ \\
$n_{3}=10$ & $q_{3}=10$ & $P F_{i}$ idem \\
$n_{4}=10$ & $q_{4}=10.5$ & $P F_{i}$ idem \\
\hline
\end{tabular}

Four combinations of $n$ and $q$ were examined to investigate the sensitivity of the results for lumpiness. For every combination of $n$ and $q$, seventeen different futures price levels for which the farmer enters the futures market were looked at. Table 1 summarizes the combinations of $n, q$ and $P F$ used in the analysis.

\subsection{Results}

The variance per futures contract is given in Figure 3. The results of our simulation suggest that the effect of lumpiness on the hedging risk of the potato futures contract decreases when the output that a farmer wishes to hedge increases. Furthermore, the hedging risk does not significantly depend on the price at which farmers enter the futures market. Thus, the market-depth risk in the potato futures market is relatively low compared with the cash-price risk and basis risk. This result is in accordance with previous research where it was concluded that the potato market is relatively deep with respect to other futures contracts, such as, hogs futures which are on the ATA also traded (Pennings et al., 1996). The covariance matrices suggest that the variance introduced by the potato futures can be attributed mainly to attributed to the basis. 


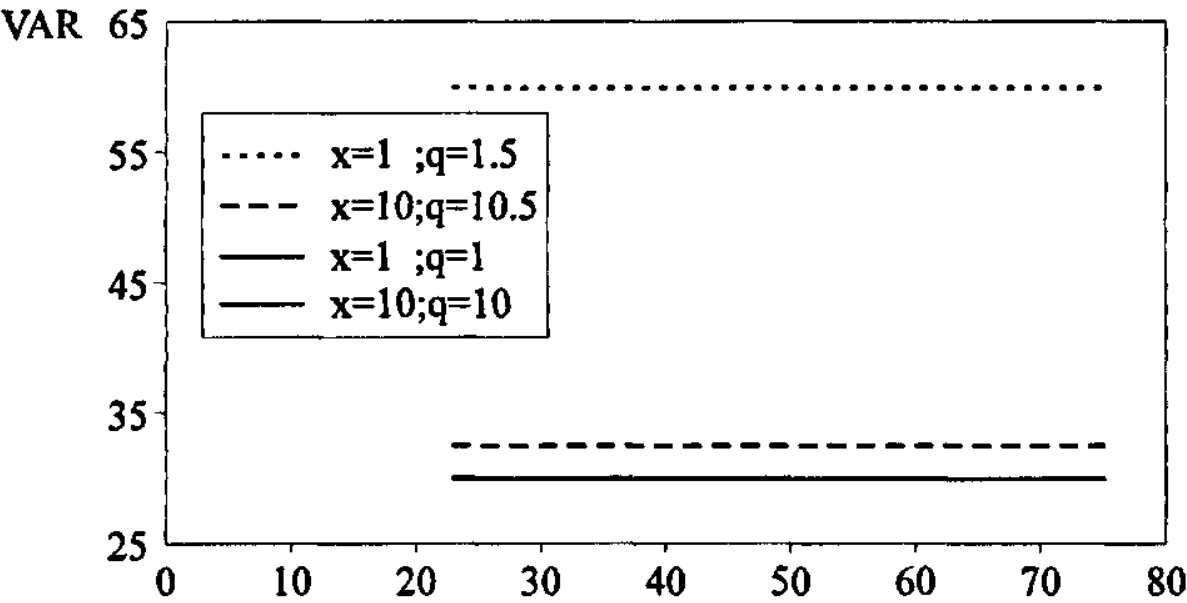

PF

Figure 3: Variance introduced by the potato futures contract traded at the Amsterdam Agricultural Futures Exchange.

From the empirical results, we conclude that futures introduce risk which must be taken into account by farmers who manage price risks. Farmers can reduce those risks, especially risks due to lumpiness, by not hedging their cash position individually, but by jointly hedging the cash positions of a group of farmers. An agricultural cooperative could do so by trading futures for a group of farmers.

Although the benefits associated with risk reduction are important factors in motivating the farmers to engage in futures trading, we are aware that potential users may also be heavily influenced by their subjective assessments of the performance and reliability of a futures market as outlined by Ennew et al. (1992).

\section{Conclusions}

As agricultural markets become freer, price volatility will increase, and thus, the need for hedging will increase. The increased opportunities for farmers to manage risk by using futures require a better understanding of the risks involved. In contrast to earlier research, we examined the decrease in both price risk through hedging as well as risks that futures introduce. Hedging with futures may lead to temporal basis risk, spatial and quality basis risk, market-depth risk, marking-to-market risk and lumpiness. These risks are particularly important to farmers hedging their output on new and small futures exchanges. The empirical results show that the hedging risk in the potato futures market in Amsterdam decreases when more futures are used. Hence, farmers who cooperate in hedging their potatoes bear less risk than farmers 
who trade separately. The price for which the farmers enter the market has almost no effect on hedging risk, i.e., marking-to-market risk was relatively low. Further research which includes other price-risk-management instruments is clearly called for in order to deepen the understanding of the risks introduced by those instruments and, hence, to provide insight into the optimal price-risk management strategies for farmers. Research which takes subjective performance into account is in progress.

\section{Acknowledgement}

We are indebted to the Amsterdam Agricultural Futures Exchange (ATA) and the Clearing Corporation (NLKKAS), especially to Rolf Wevers, for invaluable data. Furthermore, we are indebted to the board of directors of the ATA for helpful comments on an earlier draft. The authors are responsible for remaining errors.

\section{Notes}

1 Department of Marketing and Marketing Research, Wageningen Agricultural University, The Netherlands.

${ }^{2}$ Note that the words farmer and hedger are used interchangeably

${ }^{3}$ Note that the words hedging risk and futures trading risk are used interchangeably.

${ }^{4}$ We could equally well have used a long hedger in this example, because a distinction is not essential for the derivation of the hedging risk.

${ }^{5}$ In the literature, trading activity is often used as an indicator for market liquidity. However, Park and Sarkar (1994) showed that, in the case of the S\&P 500 index futures contract, changes in trading activity levels may be poor indicators of changes in market liquidity.

${ }^{6}$ This is not meant to be exhaustive.

${ }^{7}$ Making delivery on a futures is only possible when the cash position of the farmer is equal to the underlying commodity of the futures, which is seldom the case. 


\section{References}

Affleck-Graves, J., S.P. Hegde, and R.E. Miller (1994), "Trading Mechanisms and the Components of the Bid-Ask spread," Journal of Finance, 49, 1471-1488.

Bessembinder, H., and P.J. Seguin (1993), "Price Volatility, Trading Volume, and Market Depth: Evidence from Futures Markets," Journal of Financial and Quantitative Analyses, 28, 21-39.

Black, G.D. (1986), "Success and Failure of Futures Contracts Theory and Empirical Evidence," Monograph 1986-1, Salomon Brothers Center for the Study of Financial Institutions, New York.

Bosch, J.D., and J.C. Johnson (1992), "An Evaluation of Risk Management Strategies for Dairy Farms," Southern Journal of Agricultural Economics, 24, 173-182.

Brennan, M.J., and E.S. Schwartz (1990), "Arbitrage in Stock Index Futures," Journal of Business, 63, S7-31.

Brorsen, B. (1989), "Liquidity Costs and Scalping Returns in the Com Futures Market," Journal of Futures Markets, 9, 225-236.

Camerer, C.F., and H. Kunreuther (1989), "Decision Process for Low Probability Events: Policy Implications," Journal of Policy Analysis and Management, 8, 565-592.

Chan, L.K.C., and J. Lakonishok (1995), "The Behavior of Stock Prices Around Institutional Trades," Journal of Finance, 50, 1147-1174.

Christie, W., and P. Schultz (1994), "Market Structure and Liquidity: a Transaction Data Study of Exchange Listing," Journal of Financial Intermediation, 3, 300-326.

Christic, W., and P. Schultz (1995), "Market Structure and the Intraday Pattern of Bid-Ask Spreads for NASDAQ Securities," Journal of Business, 69, 35-60.

Castelino, M.G., J.C. Francis, and A. Wolf (1991), "Cross-Hedging: Basis Risk and Choice of the Optimal Hedging Vehicle," Financial Review, 26, 179-210.

Chang, J.S.K., and L. Shanker (1986), "Hedging Effectiveness of Currency Options and Currency futures," Journal of Futures Markets, 6, 289-305.

Chang, J.S.K, and H. Fang (1990), "An Intertemporal Measure of Hedging Effectiveness," The Journal of Futures Markets, 10, 307-321.

Dwight, G. (1985), "Theory of the Firm With Joint Price and Output Risk and a Forward Market," American Journal of Agricultural Economics, 67, 630-635.

Ederington, L.H. (1979), "The Hedging Performance of the New Futures Markets," Journal of Finance, 34, 157-170.

Edwards, F.R., and M.S. Canter (1995), "The Collapse of Metallgesellschaft: Unhedgeable Risks, Poor Hedging Strategy, or Just Bad Luck," Journal of Futures Markets, 15, 212. 264.

Ennew, C., C.W. Morgan, and T.I. Rayner (1992)," Objective and Subjective Influences on the Decision to Trade on the London Potato Futures Market," Journal of Agricultural Economics, 43, 160-174.

Figlewski, S. (1984), "Hedging Performance and Basis Risk in Stock Index Futures," Journal of Finance, 39, 657-669.

Figlewski, S., Y. Landskroner, and W. Silber (1991), "Tailing the Hedge: Why and How," Journal of Futures Markets, 11, 200-212.

Franckle, C.T. (1980), "The Hedging Performance of New Futures Markets: Comment," Journal of Finance, 35, 1273-1279.

Gjerde, O. (1987), "Measuring Hedging Effectiveness in a Traditional One-Period Portfolio Framework," Journal of Futures Markets, 7, 663-674.

Grossman, S.J. (1986), “An Analysis of the Role of 'Insider Trading' on Futures Markets," Journal of Business, 59, 129-146. 
Hasbrouck, J., and R.A. Schwartz (1988), "Liquidity and Execution Costs in Equity Markets," Journal of Portfolio Management, Spring, 10-16.

Hill, J., and T. Schneeweis (1982), "The Hedging Effectiveness of Foreign Currency Futures," Journal of Financial Research, 5, 95-104.

Howard, C., and L. D'Antonio (1984), "A Risk-Return Measure of Hedging Effectiveness," Journal of Financial and Quantitative Analysis, 19, 101-112.

Hsin, C-W, J. Kuo, and C.W. Lee (1994), "A New Measure to Compare the Hedging Effectiveness of Foreign Currency Futures Versus Options," Journal of Futures Markets, 14, 685-707.

Jolly, R.W. (1983), "Risk Management in Agriculture Production," American Journal of Agricultural Economics, 65, 1107-1113.

Kumar, P., and D.J. Seppi, (1994), "Information and Index Arbitrage," Journal of Business 67, 481-509.

Kyle, A.S. (1985), "Continuous Auctions and Insider Trading," Econometrica, 53, 13 I 5-1335.

Lehmann, B., and D.M. Modest (1994), "Trading and Liquidity on the Tokyo Stock Exchange: a Bird's Eye View," Journal of Finance, 49, 951-982.

Lien, D.H.D. (1993), "Risk-Return Measures of Hedging Effectiveness: the Case of Multiple Cash and Futures Markets," Managerial and Decision Economics, 14, 71-74.

Lindahl, M. (1989), “Measuring Hedging Effectiveness with $\mathrm{R}^{2}$ : A Note," Journal of Futures Markets, 9, 469-475.

Lippman, S., and J. McCall (1986), "An Operational Measure of Liquidity," American Economic Review, 76, 43-55.

Liu, S-M., W.B. Brorsen, C.M. Oellermann, and P.L. Farris (1994), "Forecasting the Nearby Basis of Live Cattle," Journal of Futures Markets, 14, 259-273.

Naik, G., and R.M. Leuthold (1988), "Cash and Futures Price Relationships for Nonstorable Commodities: An Empirical Analysis Using a General Theory," Western Journal of Agricultural Economics, 13, 327-338.

Netz, J.S. (1996), "An Empirical Test of the Effect of Basis Risk on Cash Market Positions," Journal of Futures Markets, 16, 289-311.

Overdahl, J.A., and D.R. Starleaf (1986), "The Hedging Performance of the CD Futures Market," Journal of Futures Markets, 6, 71-81.

Paroush, J., and A. Wolf (1989), "Production and Hedging Decisions in the Presence of Basis Risk, Journal of Furures Markets 9, 547-563.

Park H.Y. and, A. Sarkar (1994), "Measuring Changes in Liquidity of the Futures Market, Working paper, Office for Futures and Options Research University of Illinois at Urbana-Champaign.

Pennings, J.M.E., W.E. Kuiper, F. ter Hofstede, and M.T.G. Meulenberg (1996), "The Underlying Structure of Futures Market Depth," Proceeding of the 47th Seminar of the EAAE, Agricultural Marketing and Consumer Behavior in A Changing World, 333-345.

Pennings, J.M.E. and M.T.G. Meulenberg (1997),"Hedging Efficiency: A Futures Exchange Management Approach," Forthcoming Journal of Futures Markets.

Pirrong, S.C., R. Kormendi, and P. Meguire (1994), "Multiple Delivery Points, Pricing Dynamics, and Hedging Effectiveness in Futures Markets For Spatial Commodities," Journal of Futures Markets, 14, 545-573.

Thompson, S.R., and M.L. Waller (1987), "The Execution Cost of Trading in Commodity Futures Markets," Food Research Institute Studies 20, 141-163.

Trapp, J.N., and F.C. Eilrich (1991), "An Analysis of Factors Affecting Oklahoma City Feeder Cattle Basis," Applied Commodity Price Analysis, Forecasting, and Market Risk Management, Proceedings of the NCR-134 Conference, pp 180-192. 
Wilson, W.W. (1984), "Hedging Effectiveness of U.S. Wheat Futures Markets," Review of Research in Futures Markets, 3, 64-79.

Working, H. (1962), "New Concepts Conceming Futures Markets and Prices," American Economic Review, 52, 431-59. 